\title{
INTENSIDADE DE IRRIGAÇÃO E MANEJO DA ADUBAÇÃO NITROGENADA DE COBERTURA NO MILHO EM SISTEMA DE PLANTIO DIRETO CONSOLIDADO
}

Fernando Arnuti ${ }^{1}$, Diego Cecagno ${ }^{1}$, Amanda Posselt Martins ${ }^{1}$, Fabrício Balerini ${ }^{1}$, Egon José Meurer ${ }^{1}$, Paulo Regis Ferreira da Silva ${ }^{2}$

${ }^{1}$ Universidade Federal do Rio Grande do Sul - UFRGS, Programa de Pós-Graduação em Ciência do Solo. ${ }^{2}$ Programa de Pós-Graduação em Fitotecnia. E-mail: fernando.arnuti@gmail.com

\section{RESUMO}

O objetivo desta pesquisa foi avaliar como o manejo da adubação nitrogenada em cobertura no milho e lâminas de irrigação afetam a dinâmica do nitrogênio no perfil do solo e o rendimento de grãos de milho. Foi considerada uma área experimental que vem sendo cultivada em sistema plantio direto há 22 anos, em Eldorado do Sul/RS. Os tratamentos constaram da combinação de manejos de nitrogênio em cobertura (testemunha sem nitrogênio em cobertura, dose única de $300 \mathrm{~kg} \mathrm{ha}^{-1}$ e essa dose parcelada em duas vezes) e lâminas de irrigação $(20$ e $100 \mathrm{~mm}$ ). As amostragens de solo foram realizadas dez dias após a primeira adubação de nitrogênio em cobertura e dez dias após a segunda adubação de nitrogênio em cobertura. Independentemente da lâmina de irrigação, ocorreu o aumento nos teores de nitrato nas camadas subsuperficiais (20-30 e 30-40 cm) após a aplicação das doses de nitrogênio em cobertura. O parcelamento da adubação nitrogenada foi uma alternativa eficiente para diminuir os teores de nitrato nas camadas subsuperficiais do solo, para ambas as lâminas de irrigação. Entretanto, isso não se refletiu em ganho de produtividade e em retorno econômico quando comparado à aplicação única de nitrogênio em cobertura, independentemente da lâmina de irrigação.

Palavras-chave: estoque de nitrogênio; parcelamento da adubação nitrogenada; rendimento de grãos.

\section{NITROGEN MANAGEMENT IN COVERAGE IN IRRIGATED MAIZE IN A LONG TERM NO-TILL SYSTEM}

\begin{abstract}
The objective of this research was to evaluate how the management of nitrogen fertilization in corn and irrigation rates affects the nitrogen dynamics in the soil profile and corn grain yield. For this, was evaluated an experimental area which has been cultivated in no-tillage system since 22 years ago, in Eldorado do $\mathrm{Sul} / \mathrm{RS}$. Treatments consisted of the combination of nitrogen management in coverage (control without nitrogen topdressed, single application of $300 \mathrm{~kg} \mathrm{ha}^{-1}$ and this dose splitted in two times) and irrigation rates $(20$ and $100 \mathrm{~mm}$ ). Soil samples were taken ten days after the first fertilizer nitrogen in coverage and ten days after the second fertilizer $\mathrm{N}$ in coverage. Regardless of the rate, irrigation promoted the increase in nitrate content in subsurface layer $(20-30$ and $30-40 \mathrm{~cm})$ after the application of nitrogen cover doses. The nitrogen splitted fertilization is an effective alternative to reduce the nitrate content in subsurface soil layers, for both irrigation rates. However, this is not reflected in higher yields and economic returns when compared to single application of nitrogen, regardless of the irrigation rate.
\end{abstract}

Keywords: nitrogen stock; nitrogen splitted fertilization; grain yield.

\section{INTRODUÇÃO}

O milho (Zea mays L.) é uma das culturas de maior importância econômica no agronegócio brasileiro, não só do ponto de vista econômico, em função da extensa área cultivada, mas também nutricional, em razão da diversidade de utilização, em que se destacam a alimentação humana e animal (DÖBEREINER et al., 1995). Dentre os nutrientes necessários para o crescimento dessa cultura, o nitrogênio (N) ganha destaque, sendo o nutriente absorvido em maior quantidade.

Em razão disso, o milho é altamente responsivo a esse nutriente, apresentando 
incrementos em várias características que influenciam o rendimento de grãos (OHLAND et al., 2005). Essa condição tem possibilitado aos produtores que adotam alto nível tecnológico o uso de elevadas doses de $\mathrm{N}$ em cobertura, resultando na obtenção de altos rendimentos. Contudo, o aproveitamento do $\mathrm{N}$ pelo milho decresce com o aumento da dose aplicada, em vista do suprimento exceder às necessidades da cultura, no momento de sua aplicação. Na cultura do milho, o aproveitamento raramente ultrapassa $50 \%$ do $\mathrm{N}$ aplicado como fertilizante mineral (LARA CABEZAS et al., 2004), em razão do $\mathrm{N}$ aplicado ao solo estar sujeito a perdas (SILVA et al., 2006).

Assim, o parcelamento da adubação nitrogenada de cobertura tem sido uma estratégia eficiente nas lavouras brasileiras. Isso é respaldado pelo maior aproveitamento do $\mathrm{N}$ resultante da sincronização entre as aplicações e o período de alta demanda do nutriente (SILVA et al., 2005). Entretanto, o parcelamento contribui para onerar o custo de produção, devido ao gasto adicional com a aplicação. Diante disso, a alternativa de se aplicar o $\mathrm{N}$ em cobertura em dose única tem despertado o interesse dos produtores brasileiros, pois proporciona algumas vantagens como economia de combustível, menor compactação do solo e menor amassamento de plantas. Contudo, o clima brasileiro é caracterizado pela ocorrência de altas intensidades de precipitações pluviométricas, favorecendo a movimentação do $\mathrm{N}$ no solo, principalmente na forma nítrica $\left(\mathrm{N}^{-\mathrm{NO}_{3}}{ }^{-}\right)$ (CERETTA et al., 2007). O mesmo fenômeno ocorre em áreas sob irrigação (MENDES et al., 2015).

A alta mobilidade do $\mathrm{NO}_{3}^{-}$no solo justifica a preocupação em relação ao manejo da adubação nitrogenada em solos agrícolas (VANOTTI; BUNDY, 1994). A lixiviação do nitrato é um fenômeno físico, favorecido pela baixa energia de ligação aos argilominerais e à matéria orgânica (MO) (REISENAUER, 1978), podendo, assim, ser perdido para as camadas subsuperficiais do perfil. A movimentação de nitrato para camadas profundas é indesejável, pois, além de não ser absorvido pelas plantas, pode contaminar as águas subterrâneas (AULAKH et al., 2000). Em anos com precipitações pluviométricas bem distribuídas, a lixiviação pode não ser problema, por haver um balanço entre a água adicionada e a evapotranspiração da cultura. Porém, a lixiviação é preocupante quando as chuvas são intensas, havendo a necessidade do parcelamento dos fertilizantes nitrogenados para diminuir esse risco.

Diante desse cenário, o pouco conhecimento dos efeitos de precipitações pluviais intensas após a aplicação da adubação nitrogenada de cobertura pode comprometer a busca de altos rendimentos de grãos na cultura do milho no sul do Brasil. Assim, o objetivo desta pesquisa foi avaliar como o manejo da adubação nitrogenada em cobertura no milho e as lâminas de irrigação afetam a dinâmica do $\mathrm{N}$ no perfil do solo e o rendimento de grãos de milho.

\section{MATERIAL E MÉTODOS \\ Caracterização da área experimental}

Esse estudo foi realizado no ano agrícola 2012/13 em uma área experimental que vem sendo conduzida em semeadura direta desde 1992, em que o milho sempre entra em rotação com soja, como cultura de estação quente, e em sucessão a aveia preta (Avena strigosa), como cobertura de solo no outonoinverno, na Estação Experimental Agronômica (EEA) da Universidade Federal do Rio Grande do Sul. A EEA se localiza no município de Eldorado do Sul $\left(30^{\circ} 05^{\prime}\right.$ latitude Sul, $51^{\circ} 39^{\prime}$ longitude Oeste e altitude de $42 \mathrm{~m}$ ), região ecoclimática da Depressão Central do Estado do Rio Grande do Sul, Brasil. O clima da região é subtropical úmido de verão quente, do tipo "Cfa" conforme a classificação climática de Köppen, com temperatura média de $18,8{ }^{\circ} \mathrm{C}$ e precipitação anual de $1.455 \mathrm{~mm}$. O solo da área experimental é classificado como Argissolo Vermelho Distrófico típico, com textura superficial franco argilo arenosa.

\section{Condução do experimento e tratamentos utilizados}

O milho sucedeu ao cultivo de aveia preta como cobertura de solo no outono-inverno. A adubação na semeadura da aveia preta constou da aplicação de $200 \mathrm{~kg} \mathrm{ha}^{-1}$ da fórmula 05-30-15 $\left(\mathrm{N}, \mathrm{P}_{2} \mathrm{O}_{5}, \mathrm{~K}_{2} \mathrm{O}\right.$, respectivamente). No início do perfilhamento, foi aplicado a lanço em cobertura $45 \mathrm{~kg} \mathrm{ha}^{-1}$ de $\mathrm{N}$, na forma de ureia. A sua dessecação foi realizada aos 45 dias antes da semeadura do milho. Antecedendo a semeadura do milho, fez-se a coleta de amostras de solo até a profundidade de $40 \mathrm{~cm}$, para sua caracterização química e teor de argila (Tabela 1). 
Tabela 1. Características químicas do solo e teor de argila do solo, antes da aplicação dos manejos de nitrogênio em cobertura e lâminas de irrigação

\begin{tabular}{|c|c|c|c|c|c|c|c|c|}
\hline \multirow{2}{*}{ Camada } & \multirow{2}{*}{ Argila } & \multirow{2}{*}{$\mathrm{MO}^{(1)}$} & \multicolumn{3}{|c|}{ Cátions trocáveis } & \multirow{2}{*}{$\mathrm{CTC}_{\mathrm{pH} 7,0}{ }^{(4)}$} & \multirow{2}{*}{$P^{(3)}$} & \multirow{2}{*}{$\mathrm{K}^{(3)}$} \\
\hline & & & $\mathrm{Ca}^{2+(2)}$ & $\mathrm{Mg}^{2+(2)}$ & $A l^{3+(3)}$ & & & \\
\hline $\mathrm{cm}$ & \multicolumn{2}{|c|}{---- $\mathrm{g} \mathrm{kg}^{-1}----$} & \multicolumn{4}{|c|}{-------- $\mathrm{mmol}_{\mathrm{c}} \mathrm{dm}^{-3}$} & \multicolumn{2}{|c|}{$--\mathrm{mg} \mathrm{dm}^{-3}--$} \\
\hline $0-10$ & 256 & 22,3 & 37 & 13 & 4 & 97 & 47 & 187 \\
\hline $10-20$ & 299 & 15,0 & 20 & 10 & 18 & 94 & 29 & 121 \\
\hline $20-30$ & 360 & 16,3 & 18 & 9 & 37 & 130 & 18 & 98 \\
\hline $30-40$ & 430 & 16,0 & 18 & 9 & 43 & 143 & 19 & 94 \\
\hline
\end{tabular}

${ }^{(1)}$ Matéria orgânica; ${ }^{(2)} \mathrm{KCl}\left(1 \mathrm{~mol} \mathrm{~L}^{-1}\right) ;{ }^{(3)}$ Mehlich-1; ${ }^{(4)}$ Capacidade de troca de cátions em pH 7,0.

A semeadura do milho foi realizada com espaçamento entrelinhas de $50 \mathrm{~cm}$ utilizando-se o híbrido Pionner $30 \mathrm{R} 50 \mathrm{H}$, obtendo-se uma população final ao redor de 80.000 plantas $\mathrm{ha}^{-1}$. A adubação de base foi realizada de acordo com a análise do solo e seguiu as indicações técnicas (CQFS RS/SC, 2004), para a obtenção de altos rendimentos (19 Mg ha ${ }^{-1}$ ), utilizando-se $600 \mathrm{~kg}$ ha ${ }^{-1}$ da fórmula 05-20-20.

Os tratamentos testados foram: duas lâminas de irrigação (20 e 100 mm) após nove dias da primeira adubação nitrogenada de cobertura (estádio V7-V8) combinados com três manejos de $\mathrm{N}$ em cobertura [testemunha (sem $\mathrm{N}$ em cobertura), aplicação única de $300 \mathrm{~kg} \mathrm{ha}^{-1}$ (no estádio V5-V6) e aplicação parcelada de $300 \mathrm{~kg}$ ha $^{-1}$ (150 kg ha ${ }^{-1}$ no estádio V5-V6 e $150 \mathrm{~kg} \mathrm{ha}^{-1}$ no estádio V11-V12)]. Essas lâminas de irrigação correspondem a uma precipitação de baixa e alta intensidade, respectivamente. $O$ delineamento experimental foi de blocos ao acaso em parcelas subdivididas, com três repetições. Na parcela principal $\left(320 \mathrm{~m}^{2}\right)$ foram alocadas as lâminas de irrigação e nas subparcelas $\left(20 \mathrm{~m}^{2}\right)$ foram alocados os manejos de $\mathrm{N}$ em cobertura.
Os estádios fenológicos do milho foram determinados de acordo com a escala de Ritchie et al. (1993). A quantidade de água aplicada foi medida pela leitura indicada nos pluviômetros dispostos no centro das parcelas. O sistema de irrigação era desligado quando atingia a quantidade de água desejada. A fonte de $\mathrm{N}$ utilizada foi a ureia ( $45 \%$ de N) com inibidor da urease (concentração de 0,05 \%). As lâminas de irrigação de 20 e $100 \mathrm{~mm}$ foram aplicadas apenas após a primeira adubação nitrogenada, mas houve irrigação suplementar de $20 \mathrm{~mm}$ após as duas aplicações do $\mathrm{N}$ para dissolver os grânulos de ureia e favorecer a incorporação ao solo do $\mathrm{N}$. Durante todo o ciclo de desenvolvimento do milho irrigou-se por aspersão, de forma uniforme em todo o experimento, sempre que o potencial de água do solo, medido por tensiômetros instalados a $20 \mathrm{~cm}$ de profundidade era inferior a $-0,04 \mathrm{MPa}$. Em adição aos $371 \mathrm{~mm}$ de precipitação pluviométrica no período de cultivo, foram adicionados por irrigação $439 \mathrm{~mm}$ de água de outubro a fevereiro, aplicando em cada rega uma lâmina em torno de $25 \mathrm{~mm}$ por irrigação (Figura 1). 
Figura 1. Distribuição das precipitações pluviométricas e irrigações suplementares durante o desenvolvimento do milho, ano agrícola 2012/13. O (N) indica os manejos de nitrogênio em cobertura nos estádios V5-6 e V11-12. O (•) indica a primeira e segunda época de amostragens do solo nos estádios V7-8 e V14-15, respectivamente. A $(\downarrow)$ indica a diferenciação das lâminas de irrigação no estádio V7-8.

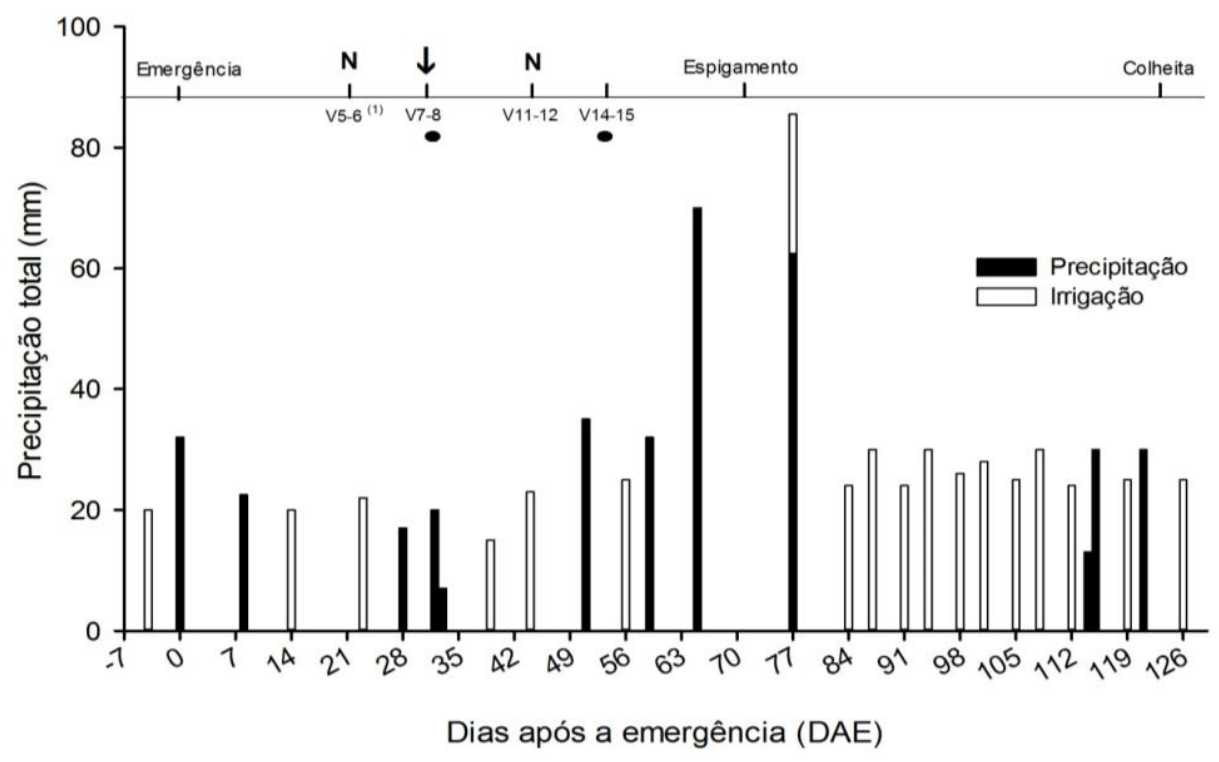

\section{Coleta do solo e determinações}

O solo foi coletado em quatro camadas $(0-10,10-20,20-30$ e $30-40 \mathrm{~cm})$ com trado holandês em duas épocas. A primeira época de amostragem ocorreu aos 10 dias após a aplicação da primeira adubação nitrogenada de cobertura, ou seja, um dia após a aplicação das duas lâminas diferentes de irrigação (estádio V7-8). A segunda época de amostragem do solo ocorreu aos 10 dias após a segunda adubação nitrogenada de cobertura (estádio V14-15). Foram coletadas seis subamostras em cada subparcela, sendo duas sobre as linhas de adubação e quatro nas entrelinhas. As amostras compostas foram mantidas resfriadas em caixas de isopor, transportadas até o laboratório e preservadas em câmara fria a $4{ }^{\circ} \mathrm{C}$.

A determinação do $\mathrm{N}$ mineral foi realizada pelo método de Kjeldahl (TEDESCO et al., 1995), em uma alíquota de solo de $5 \mathrm{~g}$ em base úmida. Considerou-se como $\mathrm{N}$ mineral total contido no solo a soma do amônio $\left(\mathrm{N}^{-} \mathrm{NH}_{4}^{+}\right)$e N$\mathrm{NO}_{3}{ }^{-}$. Após a determinação dos teores, foram calculados os estoques, considerando os valores de densidade do solo de 1,59, 1,66, 1,58 e 1,57 kg $\mathrm{dm}^{-3}$ para as camadas de $0-10,10-20,20-30$ e $30-40 \mathrm{~cm}$, respectivamente.

Outra alíquota de solo foi seca em estufa de circulação forçada de ar e peneirada em malha de $2 \mathrm{~mm}$. Com esse solo foi feita a análise de $\mathrm{pH}_{\mathrm{H} 2 \mathrm{O}}, \mathrm{P}$ e $\mathrm{K}^{+}$extraível (Mehlich-1), $\mathrm{Ca}^{+2}, \mathrm{Mg}^{+2}$ e $\mathrm{Al}^{+3}$ trocáveis $\left(\mathrm{KCl} 1 \mathrm{~mol} \mathrm{~L}^{-1}\right), \mathrm{MO}$
(Walkey-Black) e argila (pipeta), conforme descrito por Tedesco et al. (1995).

Amostragem e determinações de planta

$\mathrm{Na}$ fase do pendoamento (50\% das plantas pendoadas) foram coletadas quatro plantas em cada subparcela para determinação do $\mathrm{N}$ acumulado nesse estádio e o rendimento da matéria seca (MS) da parte aérea. As plantas foram secas em estufa de circulação forçada de ar à temperatura de $55 \pm 5{ }^{\circ} \mathrm{C}$, até atingir peso constante. $\mathrm{O} N$ acumulado nas plantas (colmo+folhastespigas) foi determinado por digestão ácida e destilação de arraste de vapor em semimicro Kjeldhal (TEDESCO et al., 1995). O rendimento de grãos ( $\mathrm{Mg} \mathrm{ha}{ }^{-1}$ ) foi obtido pela colheita manual das espigas das plantas da área útil de cada subparcela $\left(10 \mathrm{~m}^{2}\right)$, sendo os resultados expressos com $13 \mathrm{~g} \mathrm{~kg}^{-1}$ de umidade.

\section{Análise estatística}

A análise estatística foi realizada de forma separada para cada época de amostragem do solo, pela instabilidade das formas minerais de $\mathrm{N}$ e por não haver sentido prático de sua comparação. Para as variáveis $\mathrm{N}-\mathrm{NH}_{4}{ }^{+}, \mathrm{N}-\mathrm{NO}_{3}{ }^{-}$e N mineral total, foi utilizado o seguinte modelo: $Y_{i j k l}$ $=\mu+B_{i}+I_{j}+$ erro a (ij) $+M_{k}+I_{j} M_{k}+$ erro $b(i j k)+$ $C_{1}+\operatorname{erroc}(\mathrm{il})+\mathrm{I}_{\mathrm{j}} C_{1}+\mathrm{M}_{\mathrm{k}} \mathrm{C}_{\mathrm{l}}+\mathrm{I}_{\mathrm{j}} \mathrm{M}_{\mathrm{k}} \mathrm{C}_{1}+$ erro d (ijkl) em que $\mu$ : média geral do experimento; $\mathrm{B}$ : blocos (i:1,2,3); I: irrigação (j:1,2); $M$ : manejo de $N$ em cobertura $(k: 1,2,3)$ e erro: erro experimental.

Para as avaliações de rendimento de MS da parte aérea, $\mathrm{N}$ acumulado na parte aérea das plantas no pendoamento e o rendimento de 
grãos foi utilizado o modelo: $Y_{i \mathrm{jkl}}=\mu+B_{i}+I_{j}+$ erro a (ij) $+M_{k}+l_{j} M_{k}+$ erro b (ijk) em que $\mu$ : média geral do experimento; $\mathrm{B}$ : blocos (i:1,2,3); l: irrigação (j:1,2); $\mathrm{M}$ : manejo de $\mathrm{N}$ em cobertura $(k: 1,2,3)$ e erro: erro experimental. Assim, os dados foram submetidos à análise de variância (ANOVA) utilizando-se o procedimento de medidas repetidas no tempo (REPEATED), com estrutura de covariância auto-regressiva de primeira ordem $[A R(1)]$ para a variável $\mathrm{pH}\left(\mathrm{H}_{2} \mathrm{O}\right)$ e componente simétrica (CS) para as variáveis $\mathrm{N}$ $\mathrm{NH}_{4}{ }^{+}, \mathrm{N}-\mathrm{NO}_{3}{ }^{-} \mathrm{e} \mathrm{N}$ mineral total por meio do procedimento de modelos mistos (PROC MIXED) do pacote estatístico do SAS ${ }^{\circledR}$ (Statistical Analysis System). As interações significativas na ANOVA $(p<0,05)$ tiveram suas médias comparadas pelo teste Tukey $(p<0,05)$.

\section{RESULTADOS E DISCUSSÃO}

Estoque de $\mathbf{N}$ mineral no solo anterior a adubação nitrogenada

Os estoques de $\mathrm{N}$ mineral $\left(\mathrm{N}-\mathrm{NH}_{4}{ }^{+}+\mathrm{N}\right.$ $\mathrm{NO}_{3}{ }^{-}$) nas camadas $0-10$ e $10-20 \mathrm{~cm}$ já eram altos antes mesmo da adubação nitrogenada de cobertura (acima de $300 \mathrm{~kg} \mathrm{~N} \mathrm{ha}^{-1}$ ), evidenciando, assim, a contribuição do sistema plantio direto por mais de 20 anos (Figura 2). Esses estoques foram diminuindo com a profundidade. É provável também que $\mathrm{o}$ grande estoque encontrado tenha ocorrido em virtude da mineralização do $\mathrm{N}$ da $\mathrm{MS}$ da aveia preta $(5,5 \mathrm{Mg}$ $\left.h^{-1}\right)$, uma vez que as amostras de solo foram coletadas 74 dias após sua dessecação. Ceretta et al. (2002) observaram que os resíduos de aveia preta liberam $85 \%$ de $\mathrm{N}$ até 120 dias após sua dessecação.

Figura 2. Teores de $\mathrm{N}-\mathrm{NH}_{4}{ }^{+}$e N-NO${ }_{3}{ }^{-}$e de $\mathrm{N}$ mineral $\left(\mathrm{N}-\mathrm{NH}_{4}{ }^{+}+\mathrm{N}-\mathrm{NO}_{3}{ }^{-}\right)$e valores de $\mathrm{pH}\left(\mathrm{H}_{2} \mathrm{O}\right)$ no perfil do solo antes da aplicação dos manejos de nitrogênio em cobertura e lâminas diferenciais de irrigação. Médias seguidas pela mesma letra minúscula entre as profundidades nas barras e linha, não diferem entre si pelo teste de Tukey a $5 \%$.

Estoque de $\mathrm{N}$ mineral $\left(\mathrm{kg} \mathrm{ha}^{-1}\right)$

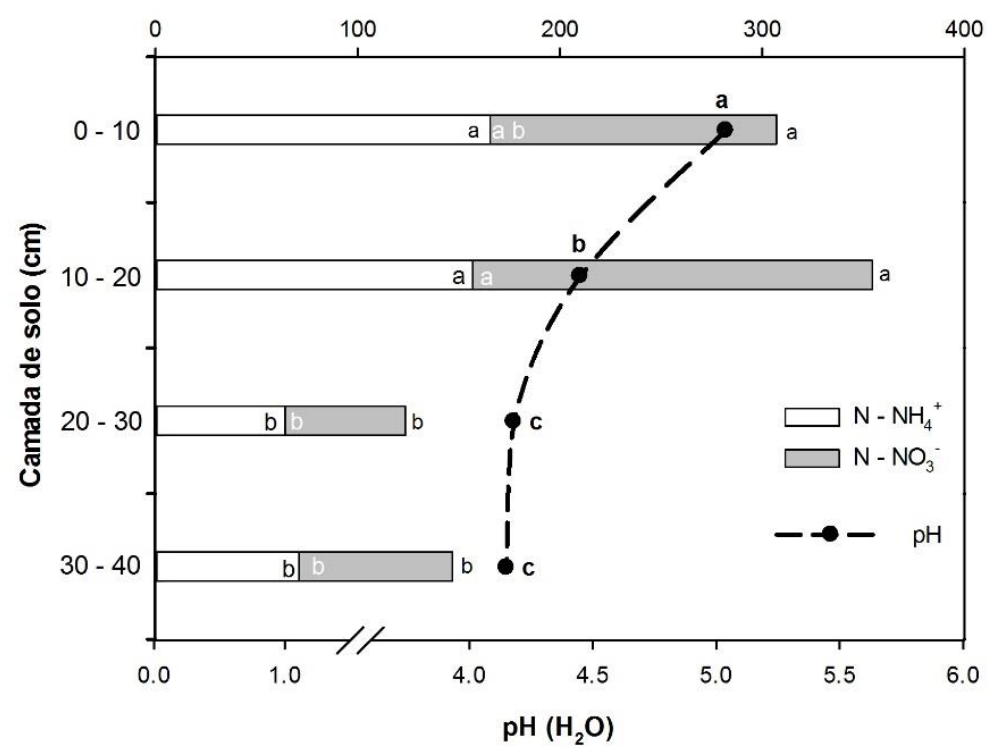

$\mathrm{O} \mathrm{pH}$ inicial do solo na área experimental era inferior a 5,0, enquadrado na faixa "Muito baixo" (CQFS RS/SC, 2004), diminuindo com a profundidade (Figura 2). A condição de acidez do solo pode ocasionar alterações na química e fertilidade do solo,

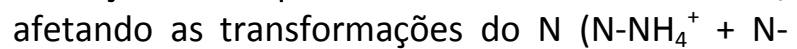
$\mathrm{NO}_{3}{ }^{-}$) no solo.

Acidez do solo após a aplicação de doses de $\mathbf{N}$ e lâminas diferenciais de irrigação

Os valores de $\mathrm{pH}$ do solo, dez dias após a aplicação de doses de $\mathrm{N}$ em cobertura, foram influenciados pelas lâminas de irrigação (Figura 3). Nas lâminas de irrigação equivalentes a $20 \mathrm{e}$ $100 \mathrm{~mm}$, a aplicação da maior dose $300 \mathrm{~kg} \mathrm{~N} \mathrm{ha}^{-1}$ reduziu $\mathrm{o} \mathrm{pH}$ do solo nas duas camadas mais superficiais $(0-10$ e $10-20 \mathrm{~cm}$ ) em relação ao tratamento testemunha, sem $\mathrm{N}$ em cobertura (Figura 3). A acidificação do solo resulta da nitrificação do amônio oriundo da matéria orgânica e/ou dos fertilizantes nitrogenados, que liberam dois íons $\mathrm{H}^{+}$na solução do solo para cada molécula de $\mathrm{NH}_{4}^{+}$transformada em $\mathrm{NO}_{3}^{-}$(RAIJ, 1991). Bolan et al. (1991) ressaltam que a ureia 
apenas acidifica o solo quando há perdas por volatilização e/ou lixiviação de $\mathrm{NO}_{3}{ }^{-}$.

Na menor lâmina de irrigação $(20 \mathrm{~mm})$, a aplicação da maior dose de N (300 kg ha $\left.{ }^{-1}\right)$ diminuiu o $\mathrm{pH}$ na camada mais superficial do solo $(0-10 \mathrm{~cm})$ em comparação à dose de $150 \mathrm{~kg} \mathrm{ha}^{-1}$ de N (Figura 3a). Por outro lado, com a aplicação da maior lâmina de irrigação $(100 \mathrm{~mm})$, a dose de $150 \mathrm{~kg} \mathrm{ha}^{-1}$ de $\mathrm{N}$ resultou em menor valor de $\mathrm{pH}$ na mesma camada avaliada em relação à dose de $300 \mathrm{~kg} \mathrm{ha}^{-1}$ de $\mathrm{N}$ (Figura 3b). Os resultados do presente estudo não são suficientes para explicar o decréscimo do $\mathrm{pH}$ do solo com a aplicação da menor dose de N, na maior lâmina de irrigação.

Na segunda época, a reaplicação de 150 $\mathrm{kg} \mathrm{ha}^{-1}$ de $\mathrm{N}$ em cobertura ocasionou um decréscimo significativo do $\mathrm{pH}$ do solo nas duas camadas mais superficiais $(0-10$ e $10-20 \mathrm{~cm})$, quando comparada ao tratamento testemunha, em ambos as lâminas de irrigação realizada aos nove dias após a aplicação da primeira parcela da adubação nitrogenada (Figura 3c,d). Esse resultado é similar ao descrito para a amostragem posterior à aplicação das lâminas de irrigação equivalentes a 20 e $100 \mathrm{~mm}$ (Figura 3a,b). A aplicação de altas doses de $\mathrm{N}$ em cobertura tende a reduzir $\mathrm{o} p \mathrm{pH}$ nas camadas superficiais do solo. Esse resultado corrobora com Lange et al. (2006), que observaram decréscimo no $\mathrm{pH}$ do solo até $20 \mathrm{~cm}$ de profundidade com a aplicação de $160 \mathrm{~kg} \mathrm{ha}^{-1}$ de N em cobertura na forma de ureia, em um Latossolo Vermelho Distrófico típico cultivado com milho. Assim, no presente trabalho, independentemente da lâmina de irrigação, a acidificação provocada pelo parcelamento da dose $150 \mathrm{~kg} \mathrm{ha}^{-1}$ de $\mathrm{N}$ em cobertura se restringiu até a camada de $30 \mathrm{~cm}$ em relação à testemunha (Figura 3c,d). É provável que a absorção de $\mathrm{NH}_{4}^{+}$ pelas plantas, com posterior extrusão de íons $\mathrm{H}^{+}$, e a remoção de cátions básicos devido à lixiviação de $\mathrm{NO}_{3}^{-}$, promoveram a acidificação do solo, justificando os resultados apresentados.

Figura 3. Valores de $\mathrm{pH}$ em função de manejos de nitrogênio em cobertura e de camadas de solo para as lâminas de irrigação de $20 \mathrm{~mm}(a, c)$ e $100 \mathrm{~mm}$ (b, d) para a primeira (a, b) e segunda (c, d) época de amostragem do solo, realizada dez dias após a primeira adubação nitrogenada de cobertura do milho irrigado. Médias seguidas pela mesma letra minúscula, na horizontal, não diferem entre si pelo teste de Tukey a $5 \%$.

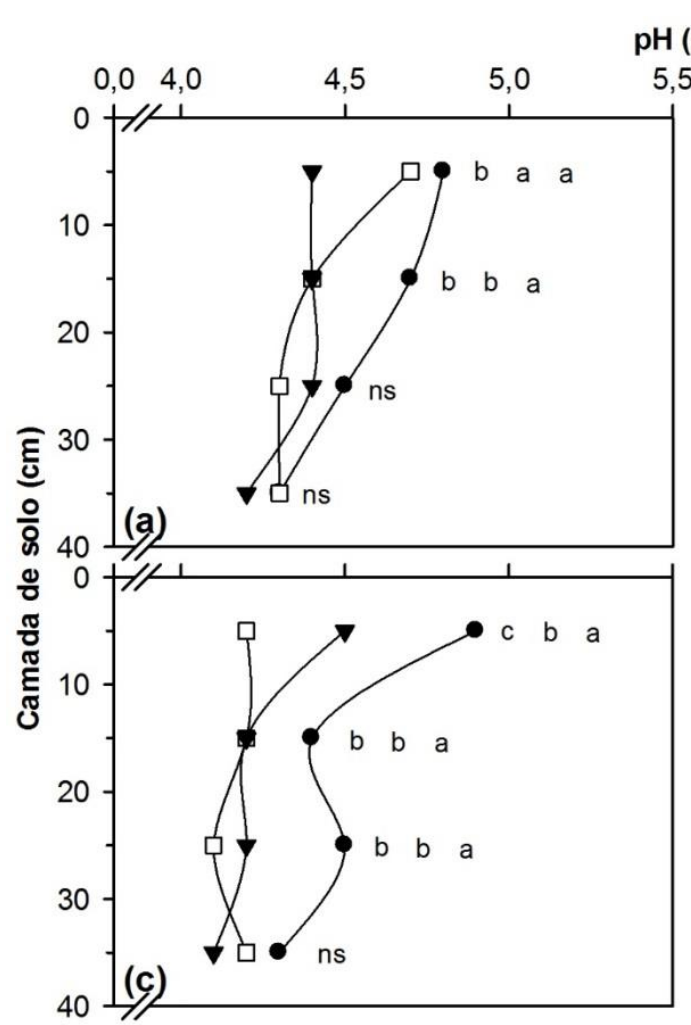

Destaca-se também, a ausência de alteração no pH do solo entre a aplicação única

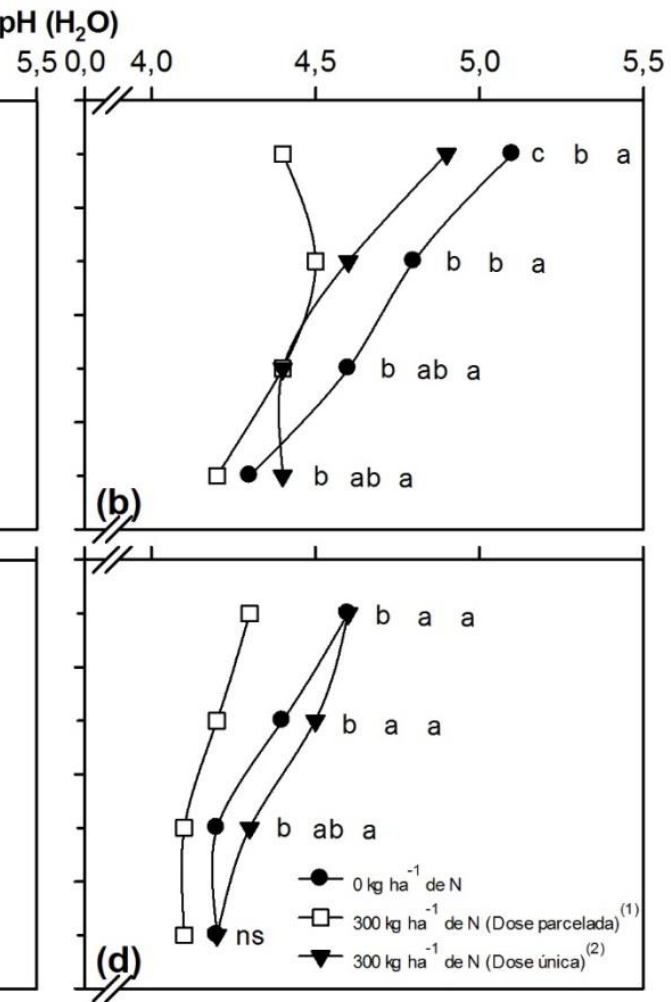

de $\mathrm{N}$ em cobertura e a testemunha sem $\mathrm{N}$ em cobertura para a maior lâmina de irrigação (100 
$\mathrm{mm}$ ) (Figura 3d). Por outro lado, na menor lâmina de irrigação $(20 \mathrm{~mm})$, foram observados menores valores de $\mathrm{pH}$, com a aplicação única de $\mathrm{N}$ em cobertura (Figura 3c). Assim, esperava-se a ocorrência de menores valores de $\mathrm{pH}$ do solo com a aplicação da maior lâmina de irrigação $(100 \mathrm{~mm})$, pois a acidificação do solo também está associada à depleção de cátions básicos, devido à lixiviação de $\mathrm{NO}_{3}{ }^{-}$(MENDES et al., 2015). A remoção desses cátions aumenta as concentrações de íons $\mathrm{H}^{+}$e $\mathrm{Al}^{3+}$ no complexo sortivo, aumentando suas concentrações na solução do solo.

Estoque de $\mathbf{N}$ no solo após a aplicação de doses de $\mathbf{N}$ e lâminas diferenciais de irrigação

A adubação nitrogenada de cobertura aumentou os estoques de $\mathrm{N}-\mathrm{NH}_{4}{ }^{+}$no perfil do solo em ambas as lâminas de irrigação em relação à testemunha (Figura 4a,b). A adição de $300 \mathrm{~kg} \mathrm{ha}^{-1}$ favoreceu o maior estoque de $\mathrm{N}-\mathrm{NH}_{4}{ }^{+}$ em todas as camadas, quando aplicada a lâmina de $20 \mathrm{~mm}$ (Figura 4a). Entretanto, na maior lâmina de irrigação $(100 \mathrm{~mm})$ a aplicação da dose de $150 \mathrm{~kg} \mathrm{ha}^{-1}$ de $\mathrm{N}$ resultou em maiores estoques de $\mathrm{N}-\mathrm{NH}_{4}{ }^{+}$em relação à dose de $300 \mathrm{~kg}$ $\mathrm{ha}^{-1}$ de $\mathrm{N}$ na camada superficial $(0-10 \mathrm{~cm})$ (Figura 4b). Normalmente, $\mathrm{O} \mathrm{NH}_{4}^{+}$tende a permanecer em torno do local de aplicação do fertilizante devido à adsorção eletrostática às cargas negativas do solo (WANG; ALVA, 1996). Além disso, o maior teor de $\mathrm{NH}_{4}{ }^{+}$com a aplicação da dose de $150 \mathrm{~kg} \mathrm{ha}^{-1}$ de $\mathrm{N}$ pode estar relacionado ao baixo $\mathrm{pH}$ do solo na camada 0 - 10 cm (Figura 3b). De acordo com Bussink (1992), em condições de $\mathrm{pH}$ ácido, a espécie química predominante é $\mathrm{NH}_{4}^{+}$. Isto pode ser explicado pelo processo de nitrificação, que é mediado pelas bactérias dos gêneros Nitrosomonas e
Nitrobacter, sendo essas muito sensíveis a valores de $\mathrm{pH}$ menores que 6,0 e têm atividade nula em pH menor que 4,5 (MOREIRA; SIQUEIRA, 2006).

De modo geral, o estoque de $\mathrm{N}$ nítrico predominou sobre o $\mathrm{N}$ amoniacal no solo, aos dez dias após a adubação nitrogenada de cobertura, independentemente da lâmina de irrigação e da dose de $\mathrm{N}$ aplicada (Figura 4a,b). O predomínio de $\mathrm{N}-\mathrm{NO}_{3}{ }^{-}$sobre $\mathrm{N}-\mathrm{NH}_{4}{ }^{+}$no solo pode resultar de muitos fatores, como a lixiviação da forma nítrica no perfil do solo (CRUSCIOL et al., 2011). Assim, com a aplicação da maior dose (300 kg ha ${ }^{-1}$ de N) em cobertura sob a maior lâmina de irrigação $(100 \mathrm{~mm})$, o estoque de $\mathrm{N}-\mathrm{NO}_{3}{ }^{-}$na camada de 20 - $30 \mathrm{~cm}$ foi de $479 \mathrm{~kg} \mathrm{ha}^{-1}$ de $\mathrm{N}$, enquanto na dose de $150 \mathrm{~kg} \mathrm{ha}^{-1}$ de $\mathrm{N}$ o valor foi de $50 \mathrm{~kg} \mathrm{ha}^{-1}$ de N na mesma camada (Figura 4b). Esse alto estoque de $\mathrm{N}^{-\mathrm{NO}_{3}}{ }_{3}^{-}$na camada mais profunda deve ter sido resultado da grande quantidade de água (precipitação pluvial + irrigação $=166 \mathrm{~mm}$ de água) ocorrido no período da aplicação da maior dose de $\mathrm{N}$ em cobertura e à amostragem do solo. Fernandes et al. (2006) encontraram valor médio de $80 \mathrm{~kg} \mathrm{ha}^{-1}$ de $\mathrm{NO}_{3}^{-}$no solo a $80 \mathrm{~cm}$ de profundidade, quando aplicaram $120 \mathrm{~kg} \mathrm{ha}^{-1} \mathrm{na}$ cultura do milho e ocorreram precipitações de $615 \mathrm{~mm}$. Esses autores argumentam que o alto valor de $\mathrm{N}^{-\mathrm{NO}_{3}}{ }^{-}$obtido deveu-se à textura arenosa do solo. Esse aumento do teor de $\mathrm{N}^{-\mathrm{NO}_{3}}{ }^{-}$ nas camadas subsuperficiais deve-se à alta mobilidade do íon $\mathrm{NO}_{3}{ }^{-}$, o que facilita sua lixiviação e promove perdas desse nutriente, oferecendo ainda risco de contaminação do lençol freático (ALCÂNTARA; CAMARGO, 2005; FEY et al., 2010). 
Figura 4. Distribuição dos teores de $\mathrm{N}-\mathrm{NH}_{4}{ }^{+}$, de N-NO${ }_{3}{ }^{-}$e de $\mathrm{N}$ mineral $\left(\mathrm{N}-\mathrm{NH}_{4}{ }^{+}+\mathrm{N}-\mathrm{NO}_{3}{ }^{-}\right)$no solo em função das doses de nitrogênio em cobertura e de camadas de solo para as lâminas de irrigação de $20 \mathrm{~mm}(\mathrm{a}, \mathrm{c})$ e $100 \mathrm{~mm}(\mathrm{~b}, \mathrm{~d})$ para a primeira (a, b) e segunda (c, d) época de amostragem do solo, realizada dez dias após a primeira adubação nitrogenada de cobertura do milho irrigado. Médias seguidas pela mesma letra minúscula dentro de cada profundidade e maiúsculas entre as profundidades nas barras, não diferem entre si pelo teste de Tukey a $5 \%$.

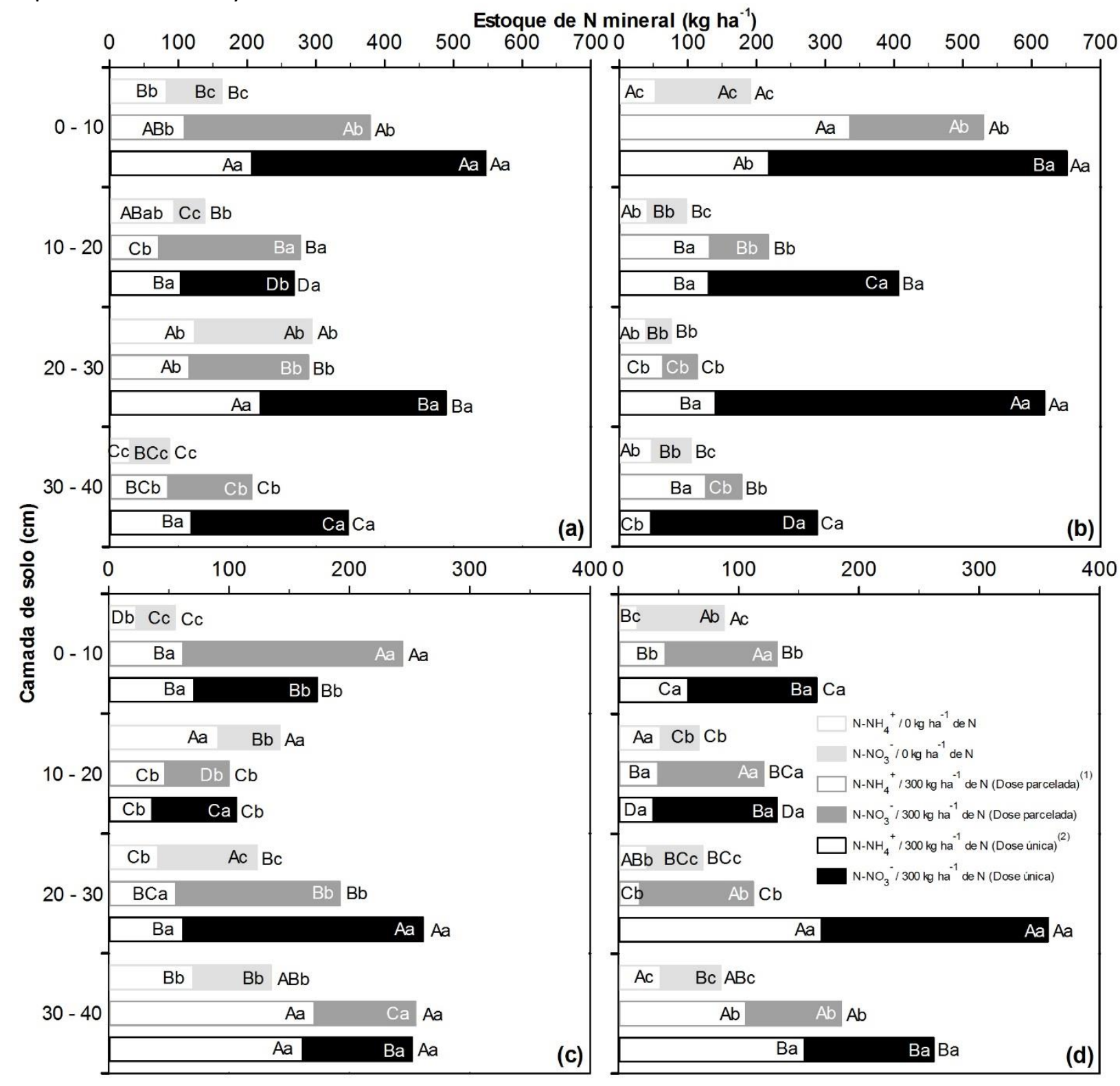

Para a segunda coleta, o parcelamento do $\mathrm{N}$ em cobertura $\left(150+150 \mathrm{~kg} \mathrm{ha}^{-1}\right.$ de $\left.\mathrm{N}\right)$ não favoreceu o aumento dos estoques de $\mathrm{N}^{-\mathrm{NH}_{4}}{ }^{+}$na camada superficial $(0-10 \mathrm{~cm})$, quando comparado com a aplicação única de N $(300 \mathrm{~kg}$ $\mathrm{ha}^{-1}$ de N) em cobertura, nas duas lâminas de irrigação (Figura 4c,d). Esperava-se que 0 parcelamento da adubação nitrogenada

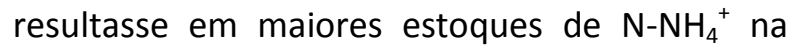
camada superficial ao contrário da dose única, por proporcionar aporte de $\mathrm{N}$ em dois momentos. No entanto, não foi constatado nesse estudo.
A comparação entre o manejo do $\mathrm{N}$ em cobertura (única e parcelada) nas duas camadas mais profundas $(20-30$ e $30-40 \mathrm{~cm}$ ) mostrou que na maior lâmina de irrigação $(100 \mathrm{~mm})$, os estoques de $\mathrm{N}^{-} \mathrm{NH}_{4}^{+}$no solo foram significativamente maiores com a aplicação única de $\mathrm{N}$ (Figura 4d). Por outro lado, na menor lâmina de irrigação $(20 \mathrm{~mm})$, não se verificou alteração no estoque de $\mathrm{N}-\mathrm{NH}_{4}{ }^{+}$no solo quando comparada às estratégias de aplicação de $\mathrm{N}$ em cobertura, para as mesmas camadas avaliadas (Figura 4c). Estes resultados evidenciam que a lâmina de irrigação é o fator determinante na lixiviação e na 
variação de distribuição no estoque de $\mathrm{N}-\mathrm{NH}_{4}{ }^{+}$no perfil do solo. De acordo com Araújo et al. (2004), a lixiviação de $\mathrm{NH}_{4}{ }^{+}$é uma realidade com a aplicação de doses usualmente recomendadas de adubos nitrogenados, mesmo em Latossolos muito argilosos. Além disso, no caso do presente trabalho, há uma predominância da textura arenosa ao longo do perfil, sendo a maior fração de areia observada na camada superficial (Tabela 1).

A distribuição dos estoques de $\mathrm{N}-\mathrm{NO}_{3}{ }^{-}$ no perfil do solo, na menor lâmina de irrigação (20 mm), indica que o parcelamento do $\mathrm{N}$ em cobertura propiciou o acúmulo de $\mathrm{N}_{-} \mathrm{NO}_{3}{ }^{-}$na camada mais superficial $(0-10 \mathrm{~cm})$ em comparação a aplicação única de $\mathrm{N}$ em cobertura (Figura 4c). Por outro lado, na mesma camada, mas na maior lâmina de irrigação $(100 \mathrm{~mm}), \mathrm{a}$ aplicação única em cobertura aumentou os estoques de $\mathrm{N}^{-\mathrm{NO}_{3}}{ }^{-}$em relação ao parcelamento do $\mathrm{N}$ em cobertura (Figura 4d). Tal comportamento não era esperado, visto que ambas as lâminas de irrigação (20 e 100 mm) receberam a mesma quantidade de água (58 $\mathrm{mm}$ ) após o parcelamento do $\mathrm{N}$ em cobertura.

$\mathrm{A}$ aplicação única do $\mathrm{N}$ em cobertura resultou em estoques superiores de $\mathrm{N}_{-} \mathrm{NO}_{3}{ }^{-}$, nas duas camadas mais profundas (20 - 30 e 30 - 40 $\mathrm{cm})$, em relação ao observado com a aplicação parcelada de $\mathrm{N}$ em ambos as lâminas de irrigação (Figura 4c,d). Esses resultados indicam a ocorrência de movimentação intensa do $\mathrm{N}-\mathrm{NO}_{3}$ da camada superficial até as camadas mais profundas. Embora 85 \% da matéria seca das raízes de milho se encontrem na camada de 0-20 $\mathrm{cm}$, as raízes que se distribuem abaixo desse limite são predominantemente raízes finas (diâmetro < 1,2 mm), com um comprimento radicular semelhante ao das camadas superficiais (VENZKE FILHO et al., 2004). Assim, essa característica levanta a hipótese de que parte do $\mathrm{N}$ possa ser aproveitado pelas raízes de camadas mais profundas.

Contudo, o acréscimo dos estoques de $\mathrm{N}-\mathrm{NO}_{3}{ }^{-}$nas camadas subsuperficiais reforça a recomendação feita por Ernani (1999) e Bortolini (2000) de que, em solos arenosos, que apresentam maior facilidade de lixiviação de $\mathrm{NO}_{3}$ , a fertilização nitrogenada em altas doses deve ser manejada em maior número de aplicações do que em solos argilosos.

Rendimento de grãos, rendimento de matéria seca e quantidade de $\mathbf{N}$ acumulado no milho

Embora a aplicação de $\mathrm{N}$ tenha aumentado o rendimento de MS da parte aérea, a quantidade de $\mathrm{N}$ acumulado no pendoamento e o rendimento de grãos de milho, esses atributos não variaram em função das lâminas de água aplicadas com irrigação, realizada aos nove dias após a aplicação da primeira parcela da adubação nitrogenada (Tabela 2).

Tabela 2. Rendimento de matéria seca e quantidade de nitrogênio acumulado na parte aérea no pendoamento e rendimento de grãos de milho em função de manejos de nitrogênio em cobertura e lâminas de irrigação aplicados aos nove dias após a primeira parcela da adubação nitrogenada

\begin{tabular}{|c|c|c|c|c|}
\hline \multirow{2}{*}{ Lâmina de irrigação ${ }^{(1)}$} & \multirow{2}{*}{ Testemunha $^{(2)}$} & \multicolumn{2}{|c|}{ Adubação de $300 \mathrm{~kg} \mathrm{~N} \mathrm{ha}^{-1}$} & \multirow{2}{*}{ Média } \\
\hline & & Única $^{(3)}$ & Parcelada ${ }^{(4)}$ & \\
\hline ------------ $\mathrm{mm}$------------ & \multicolumn{4}{|c|}{------ Rendimento matéria seca da parte aérea $\left(\mathrm{Mg} \mathrm{ha}^{-1}\right)$------ } \\
\hline 20 & 14,10 & 18,54 & 19,97 & $17,54 \mathrm{~ns}$ \\
\hline 100 & 13,73 & 17,90 & 19,73 & 17,12 \\
\hline \multirow[t]{2}{*}{ Média } & $13,92 \mathrm{~B}$ & $18,22 \mathrm{~A}$ & $19,85 \mathrm{~A}$ & \\
\hline & \multicolumn{4}{|c|}{---------- N acumulado no pendoamento $\left(\mathrm{kg} \mathrm{ha}^{-1}\right)$----------- } \\
\hline 20 & 128 & 346 & 339 & 271 ns \\
\hline 100 & 152 & 304 & 321 & 259 \\
\hline \multirow[t]{2}{*}{ Média } & $140 \mathrm{~B}$ & $325 \mathrm{~A}$ & $330 \mathrm{~A}$ & \\
\hline & \multicolumn{4}{|c|}{-------------- Rendimento de grãos (Mg ha'1) -------------- } \\
\hline 20 & 8,61 & 15,14 & 15,42 & $13,05 \mathrm{~ns}$ \\
\hline 100 & 10,02 & 15,16 & 15,17 & 13,45 \\
\hline Média & $9,32 \mathrm{~B}$ & $15,15 \mathrm{~A}$ & $15,29 \mathrm{~A}$ & \\
\hline
\end{tabular}


Considerando 0 alto custo dos fertilizantes nitrogenados e a necessidade de diminuir os custos de produção, a aplicação única de $300 \mathrm{~kg} \mathrm{ha}^{-1}$ de $\mathrm{N}$ em cobertura pode ser uma alternativa para lavouras que buscam altos rendimentos. Entretanto, a aplicação de altas doses de $\mathrm{N}$ deve ser encarada com cautela, devido à perda de $\mathrm{N}$ em decorrência do excesso disponível. Segundo Malhi et al. (2001) é necessário ter cautela na recomendação da dose, pois a recuperação do $\mathrm{N}$ dos fertilizantes, pelas plantas, é relativamente baixa, alcançando em muitos casos menos que $50 \%$.

A ausência de resposta ao parcelamento do $\mathrm{N}$ para o rendimento de grãos está de acordo com os resultados encontrados por Fontoura e Bayer (2009). Os autores observaram que, em sete anos de experimento, o parcelamento da adubação nitrogenada não se refletiu em aumento de rendimento em relação à aplicação em dose única. Além disso, a melhoria da fertilidade do solo com o passar do tempo, principalmente no sistema plantio direto, pode ter contribuído para a redução da importância do modo de aplicação dos fertilizantes nitrogenados (CERETTA et al., 2007).

Os resultados apresentados indicam que, embora a área experimental apresente $\mathrm{pH}$ inferior a 5,0, o rendimento de grãos de milho atingiu altos patamares, produzindo mais de 9 $\mathrm{Mg} \mathrm{ha}{ }^{-1}$ mesmo na ausência de $\mathrm{N}$ em cobertura (Tabela 2). As prováveis explicações para isto são a complexação do Al por ligantes orgânicos (SALET al., 1999), os elevados níveis de fertilidade e a utilização de irrigação no experimento.

\section{CONCLUSÕES}

A aplicação de altas doses de nitrogênio em cobertura diminui o $\mathrm{pH}$ do solo nas camadas superficiais, independentemente da lâmina de irrigação.

O parcelamento da adubação nitrogenada para altos rendimentos no milho é uma alternativa eficiente para diminuir os teores de nitrato nas camadas subsuperficiais do solo.

A estratégia da aplicação de nitrogênio em cobertura, única ou parcelada, não afeta o rendimento de matéria seca, a quantidade de nitrogênio acumulado na parte aérea na espiga.

\section{REFERÊNCIAS}

ALCÂNTARA, M.A.K.D.; CAMARGO O.A.D. Adsorção de nitrato em solos com cargas variáveis. Pesquisa Agropecuária Brasileira, v. 40, n. $4, \quad$ p. 2005. http://dx.doi.org/10.1590/S0100$\underline{204 X 2005000400008 .}$

ARAÚJO, A.R.D.; CARVALHO, J.L.N.; GUILHERME, L.R.G.; CURI, N.; MARQUES, J.J. Movimentação de nitrato e amônio em colunas de solo. Ciência e Agrotecnologia, v. 28, n.3, p.537-541, 2004. http://dx.doi.org/10.1590/S1413$\underline{70542004000300008 .}$

AULAKH, M.S.; KHERA, T.S.; DORAN, J.W.; SINGH, K.; SINGH, B. Yields and nitrogen dynamics in a rice-wheat system using green manure and inorganic. Soil Science Society of America Journal, v. 64, n. 5, p. 1867-1876, 2000. https://doi.org/10.2136/sssaj2000.6451867x.

BOLAN, N.S.; HEDLEY, M.J.; WHITE, R.E. Processes of soil acidification during nitrogen cycling with emphasis on legume based pastures. Plant and Soil, v. 134, n. 1, p. 53-63, 1991. https://doi.org/10.1007/BF00010717.

BORTOLINI, C.G. Eficiência do método de adubação nitrogenada em pré-semeadura do milho implantado em semeadura direta após aveia preta. 2000. 55f. Dissertação (Mestrado) Universidade Federal do Rio Grande do Sul, Porto Alegre-RS, 2000.

BUSSINK, D.W. Ammonia volatilization from grassland receiving nitrogen fertilizer and rotationally grazed by dairy cattle. Fertilizer Research, v. 33, n. 3, p. 257-265, 1992. https://doi.org/10.1007/BF01050881

CERETTA, C.A.; BASSO, C.J.; HERBES, M.G.; POLETTO, N.; SILVEIRA, M.J. Produção e decomposição de fitomassa de plantas invernais de cobertura de solo e milho, sob diferentes manejos da adubação nitrogenada. Ciência Rural, v. $32, \quad$ n. $1, \quad$ p. 49-54, 2002. http://dx.doi.org/10.1590/S010384782002000100009.

CERETTA, C.A.; SILVA, L.S.; PAVINATO, A. Manejo da adubação. In: NOVAIS, R.F.; ALVAREZ, V.V.H.; BARROS, N.F.; FONTES, R.L.F.; CANTARUTTI, R.B.; NEVES, J.C.L. Fertilidade do Solo. Viçosa: Sociedade Brasileira de Ciência do Solo, 2007. p. 851-872. 
CQFS RS/SC - Comissão de Química e Fertilidade do Solo. Manual de adubação e calagem para os Estados do Rio Grande do Sul e de Santa Catarina. Porto Alegre: Sociedade Brasileira de Ciência do Solo/Núcleo Regional Sul, 2004.

CRUSCIOL, C.A.C.; GARCIA, R.A.; CASTRO, G.S.A.; ROSOLEM, C.A. Nitrate role in basic cation leaching under no-till. Revista Brasileira de Ciência do Solo, v. 35, n. 6, p. 1975-1984, 2011. http://dx.doi.org/10.1590/S010006832011000600014.

DÖBEREINER, J.; BALDANI, V.L.D.; BALDANI, J.I. Como isolar e identificar bactérias diazotróficas de plantas não leguminosas. Brasília: EMBRAPASPI; Itaguai: EMBRAPA-CNPAB, 1995.

ERNANI, P.R. Nutrição e produtividade de espécies vegetais em sistemas de plantio direto e convencional. In: SANGOI, L.; ALMEIDA, M.L. (Orgs.). Reunião Técnica Catarinense de Milho e Feijão. Lages: UDESC/EPAGRI, 1999. p.19-30.

FERNANDES, F.C.S.; LIBARDI, P.L.; CARVALHO, L.A. Internal drainage and nitrate leaching in cornblack oat-corn succession with two split nitrogen applications. Scientia Agricola, v.63, n.5, p.483492, 2006. http://dx.doi.org/10.1590/S0103$\underline{90162006000500011 .}$.

FEY, R.; LANA, M.C.; ZOZ, T.; RICHART, A.; LUCHESE, E.B. Relações entre lixiviação de nitrato e produção de biomassa do milho com dejetos suínos provenientes de diferentes tratamentos. Revista Brasileira de Ciências Agrárias, v. 5, n. 2, p. 212-218, 2010. DOI: 10.5039/agraria.v5i2a715.

FONTOURA, S.M.V.; BAYER, C. Adubação nitrogenada para alto rendimento de milho em plantio direto na região centro-sul do Paraná. Revista Brasileira de Ciência do Solo, v. 33, n. 6, p. 1721-1732, 2009. http://dx.doi.org/10.1590/S010006832009000600021.

LANGE, A.; CARVALHO, J.L.N.; DAMIN, V.; CRUZ, J.C.; MARQUES, J.J. Alterações em atributos do solo decorrentes da aplicação de nitrogênio e palha em sistema semeadura direta na cultura do milho. Ciência Rural, v. 36, n. 2, p. 460-467, 2006. http://dx.doi.org/10.1590/S0103-

84782006000200016.
LARA CABEZAS, W.A.R.; ALVES, B.J.R.; CABALLERO, S.S.U.; SANTANA, D.G. Influência da cultura antecessora e da adubação nitrogenada na produtividade de milho em sistema plantio direto e solo preparado. Ciência Rural, v. 34, n. 4, p. 1005-1013, 2004. http://dx.doi.org/10.1590/S0103$\underline{84782004000400006 .}$

MALHI, S.S.; GRANT, C.A.; JOHNSTON, A.M.; GILL, K.S. Nitrogen fertilization management for no-till cereal production in the Canadian Great Plains: a review. Soil \& Tillage Research, v. 60, p. 101-122, $2001 . \quad$ https://doi.org/10.1016/S01671987(01)00176-3

MENDES, W.C.; ALVES JUNIOR, J.; CUNHA, P.C.R.; SILVA, A.R.; EVANGELISTA, A.W.P.; CASAROLI, D. Lixiviação de nitrato em função de lâminas de irrigação em solos argiloso e arenoso. Irriga, v.1, n.2, p.47-56, 2015. http://dx.doi.org/10.15809/irriga.2015v1n2p47

MOREIRA, F.M.S.; SIQUEIRA, J.O. Microbiologia e bioquímica do solo. Lavras: Universidade Federal e Lavras, 2002.

OHLAND, R.A.A.; SOUZA, L.C.F.; HERNANI, L.C.; MARCHETTI, M.E.; GONÇALVES, M.C. Culturas de cobertura do solo e adubação nitrogenada no milho em plantio direto. Ciência e Agrotecnologia, v. 29, n. 3, p. 538-544, 2005. http://dx.doi.org/10.1590/S1413$\underline{70542005000300005 .}$.

RAIJ, B.V. Fertilidade do solo e adubação. São Paulo: Agronômica Ceres, 1991.

REISENAUER, H.M. Absorption and utilization of ammonium nitrogen by plants. In: NIELSEN, D.R.; McDONALD, J.G. Nitrogen in the environment. London: Academic Press, 1978. p. 157-170.

RITCHIE, S.W.; HANWAY, J.J.; BENSON, G.O. How a corn plant develops. Ames: lowa State University of Science and Technology, 1993. 26 p. (Special Report; 48).

SILVA, E.C.; FERREIRA, S.M.; SILVA, G.P.; ASSIS, R.L.; GUIMARÃES, G.L. Épocas e formas de aplicação de nitrogênio no milho sob plantio direto em solo de cerrado. Revista Brasileira de Ciência do Solo, v.29, n.5, p.725-733, 2005. 
http://dx.doi.org/10.1590/S0100-

$\underline{06832005000500008 .}$

SILVA, E.C.; MURAOKA, T.; BUZETTI, S.; TRIVELIN, P.C.O. Manejo de nitrogênio no milho em Latossolo Vermelho sob plantio direto com diferentes plantas de cobertura. Pesquisa Agropecuária Brasileira, v.41, n.3, p.477-486, $2006 . \quad$ http://dx.doi.org/10.1590/S0100$\underline{204 \times 2006000300015}$.

TEDESCO, M.J.; GIANELLO, C.; BISSANI, C.A.; BOHNEN, H.; VOLKWEISS, S.J. Análise de solo, plantas e outros materiais. Porto Alegre: UFRGS, 1995. 174p. (Boletim técnico, 5).

VANOTTI, M.B.; BUNDY, L.G. An alternative rationale for corn nitrogen fertilizer recommendations. Journal of Production Agriculture, v.7, n.2, p.243-249, 1994. DOI:10.2134/jpa1994.0243.

VENZKE FILHO, S.P.; FEIGL, B.J.; PICCOLO, M.C.; FANTE JR, L.; SIQUEITA NETO, M.; CERRI, C.C. Root systems and soil microbial biomass under no-tillage system. Scientia Agricola, v.31, n.5, p.529-537, 2004. http://dx.doi.org/10.1590/S0103$\underline{90162004000500011 .}$.

WANG, F.L.; ALVA, A.K. Leaching of nitrogen from slowrelease urea sources in sandy soils. Soil Science Society of America Journal, v. 60, n. 5, p. 1454-1458, 1996.

Recebido para publicação em 11/09/2017

Revisado em 02/12/2017

Aceito em 26/01/2018 